\title{
C) HitsistórRICA
}

Prostitutas e Bebuns: o espaço urbano e os modelos de gênero presentes na Folha do Norte do Paraná (1965-1973)

Prostitutas y Bebes: el espacio urbano y los modelos de género presentes en la Folha do Norte do Paraná (1965-1973)

Gessica Aline Silva*

Resumo: O presente artigo tem por objetivo abordar as relações entre a constituição das feminilidades e as masculinidades consideradas transgressoras. Para tanto, nos voltamos aos discursos presentes na coluna policial da Folha do Norte do Paraná entre os anos de 1965 a 1973. Compreendemos que a discussão acerca dos modelos de gênero se desenvolvia de maneira articulada a projetos de sociedade construídos no contexto de crescimento de Maringá, cidade em que o periódico era produzido. Sendo assim, a figura das prostitutas e dos bebuns, sujeitos considerados indesejados nesse projeto, visto que se apresentam de maneira avessa as condutas relacionadas aos modelos de masculino e feminino, se constituíram como os principais alvos dos discursos moralizadores e normatizadores do Jornal.

Palavras-chaves: Crime; Transgressão; Imprensa; Gênero.

Resumen: Este artículo pretende abordar las relaciones entre la constitución de las feminidades y las masculinidades consideradas transgresoras. Para ello, pasamos a los discursos presentes en la columna de la policía de Folha do Norte do Paraná entre los años I965 y 1973. Entendemos que la discusión sobre modelos de género se desarrolló de manera articulada a proyectos de la sociedad construidos en el contexto de Maringá. ciudad en la que se produjo el periódico. Así, la figura de prostitutas y bebuns, temas considerados indeseables en este proyecto, ya que la conducta relacionada con los modelos de masculino y femenino, se presentan como los principales objetivos de los discursos moralizadores y normatizantes de la revista.

Palabras clave: Crimen; Trasgresión; Presione; Género.

"Mestre em História. Universidade Estadual do Oeste do Paraná - campus de Marechal Cândido Rondon. 


\section{Introdução}

A constituição de discursos, acerca dos modelos de condutas de gênero, se organiza em diferentes períodos históricos, sendo influenciada e articulada por diversos poderes. Nesta perspectiva, uma série de dualidades e oposições foram relacionados aos comportamentos femininos e masculinos, ditos como ideais e transgressores. No presente artigos abordamos o contexto brasileiro, especialmente no interior do país, tendo como referência a cidade de Maringá, entre os anos de 1965 a 1973.

Essa segunda metade do século XX é marcada, principalmente na América Latina pela instauração de regimes ditatoriais. No Brasil a Ditadura Civil-Militar constituída entre os anos de I964 a 1985 contribuiu para intensificação dos processos de controle, censura e repressão à população. A adoção de ideias conservadores e moralizantes por parte dos governos orientou políticas públicas em relação a circulação e organização dos espaços urbanos, seja nas grandes capitais ou no interior do país. Neste contexto, nos aproximamos de Maringá, cidade localizada na região noroeste do estado do Paraná, buscando perceber, a partir da perspectiva dos estudos de gênero, as políticas morais relacionadas a vigilância dos sujeitos ditos transgressores.

Para tanto, analisamos os discursos presentes nas colunas policiais do Jornal Folha do Norte do Paraná. Este periódico produzido em Maringá entre anos de I962 a 1979 com circulação diária englobando mais de 95 do estado, se consolidou como uma das principais influências na constituição e orientação dos debates acerca dos comportamentos e posturas sociais locais. Sendo assim, como argumenta Campos (I999), ao comentar o contexto maringaense nos anos 1960 e 1970 , os jornais se constituíram em porta-vozes das normatizações nos espaços urbanos, de acordo com a visão dos grupos dominantes e o poder público.

Ao analisar os discursos em circulação entre os anos de 1965 a 1973 considerarmos a estruturação e solidificação do Jornal, bem como o colapso da produção cafeeira, o crescimento da população de Maringá devido ao êxodo rural, a introdução de novos sujeitos na dinâmica local e, consequentemente, de aceleração do processo de urbanização, que modificou e trouxe para o centro dos debates a constituição dos costumes, de projetos de sociedade e de cidadãos visados para a cidade. Este contexto inspira reflexões acerca da emergência desses debates sobre o espaço urbano e suas implicações na construção de 
modelos de masculinidades e de feminilidades, bem como a problematização dos interesses e negociações dos diferentes grupos sociais.

Consideramos que homens e mulheres possuem diferentes experiências em relação a ocupação do espaço urbano. Assim, de acordo com o conceito de "gênero" proposto por Joan Scott (1994), compreendemos que as noções de masculino e feminino são construções sociais e culturais, sendo "[...] um elemento constitutivo de relações sociais baseado nas diferenças percebidas entre os sexos uma forma primeira de significar as relações de poder" (SCOTT, 1994, p. 2I). Essa perspectiva nos permite questionar as características e as representações de masculinidades e feminilidades naturalizadas no cotidiano por construtos sociais e culturais, e a contribuição da organização do poder para sua manutenção.

Dessa maneira, apresentamos uma análise de dois casos relacionados com a constituição de modelos de feminilidades e masculinidades dos sujeitos considerados transgressores, tendo como preocupação sua articulação social, suas relações de poder e os projetos sociais aos quais respondiam. A partir de um referencial teórico que nos permitisse pensar as relações entre homens e mulheres veiculados pelo Jornal, buscando compreender as complexidades das relações entre os sujeitos, bem como a relação imprensa e sociedade na constituição de performances sociais, compreendendo os jogos de poder, a vigilância e as resistências.

Sendo assim, organizamos o artigo em três tópicos que discutem o espaço urbano de Maringá e a constituição de feminilidades e masculinidades transgressoras. Para tanto, atentamos ao estudo de dois casos publicados pela Folha do Norte do Paraná no período de I965 a 1973, discutindo especificamente os discursos acerca das mulheres prostitutas e dos homens ébrios; nos atentamos as relações entre essas condutas consideradas transgressoras e os discursos morais associados as construções de gênero.

\section{O espaço urbano e a Folha do Norte do Paraná: entre discursos e ações de transformação}

O processo de construção da cidade Maringá foi, incialmente planejado pela Companhia Melhoramentos do Norte do Paraná (CMNP), ainda na primeira metade do século XX, a estratégia utilizada para ocupação da região consistiu na divisão da terra em pequenas e médias propriedades, na construção de núcleos habitacionais centrais com uma distância de $100 \mathrm{~km}$ cada, e outros centros menores, com distância de 20 a 30 km, visando facilitar as vias de comunicação, abastecimento e transporte (TOMAZ, 20IO; CHIES; YOKOO, 20I2; OLIVEIRA, 2009). 
A planificação das operações da companhia abarcou também o desenho urbano de Maringá projetado pelo urbanista Jorge de Macedo. A estrutura do espaço da cidade, por ele organizada, foi construída de acordo com a altimetria do solo, baseado no modelo inglês de cidade-jardim, subdividindo os locais em núcleos de acordo com suas funções. Dessa maneira, foram criadas as zonas do centro cívico, do comércio, da indústria, das moradias nobres, coletivas, proletárias e o cinturão verde, formado por pequenas chácaras, que visavam abastecer e criar de uma cidade planejada, racional e autônoma.

Essa preocupação com a determinação do espaço público de Maringá apresentada nos primeiros anos de sua constituição se estende por outros momentos de sua história como podemos observar na Lei Municipal no 624/1968, que definia a função e a importância do zoneamento da cidade ao explicar que este "[...] consiste na repartição do solo do município em zonas de usos distintos, objetivando o uso da terra, as densidades de população, a localização, a dimensão, o volume dos edifícios e seus usos específicos”. Ainda segundo esse texto, essas características eram fundamentais para "[...] se conseguir o desenvolvimento adequado da comunidade e o bem-estar social de seus habitantes".

Tais ações da companhia de terras, seus códigos e, posteriormente as leis municipais, interferiam na vida dos citadinos, em suas práticas de espaços e em sua circulação, fixando e distribuindo a população de acordo com suas condições sociais. Essas disposições arquitetônicas carregavam em si as pretensões e as ações que visavam o controle, a disciplina e a sujeição dos indivíduos a um mecanismo de visibilidade e de vigilância, cujos objetivos eram tornar úteis os espaços e os sujeitos, como argumenta Michel Foucault (2004) ao discorrer acerca da organização das sociedades disciplinares.

As características da constituição da cidade de Maringá esclarecem parcialmente a preocupação dos gestores públicos com o processo de crescimento urbano e a busca pelo estabelecimento de uma ordem social. O direcionamento do desenvolvimento da cidade e as tentativas de fixar as funções dos espaços públicos, buscavam determinar para quais sujeitos essas áreas eram destinadas e os usos feitos delas. Sendo assim, tais fatores influenciam na construção do espaço, mas também, da memória, dos relatos.

Segundo as colocações de Michel de Certeau (2014), principalmente de seu conceito de lugar praticado, ou seja, da compreensão de que os lugares são constituídos a partir de seus usos, dos relatos e das memórias que produzem, compreendemos que o espaço urbano de Maringá era construído por diferentes discursos que se entrecruzavam. A Folha do Norte do Paraná, ao veicular as notícias e propor problematizações sobre a cidade, criava um outro espaço urbano e que lhe era próprio. Nesse sentido, as imagens e os discursos que produzia 
eram novas feituras de espaço, parciais e direcionadas pelos interesses e pelos posicionamentos do periódico.

Nesta perspectiva, em uma matéria publicada no dia or de maio de 1965, encontramos discursos de incentivo as ações policiais de combate a vadiagem, principalmente, de "mulheres da vida" e de "bebuns" dizendo que:

Nós damos apoio a toda iniciativa policial que se orienta no sentido de moralizar a cidade, apelamos aos responsáveis pela Justiça a fim de que colaborem para exterminar os antros de vagabundagem (Folha do Norte do Paraná, I/5/1965, p. 2).

O trecho acima retirado de uma matéria publicada na coluna policial do Jornal, ao ser apresentado na terceira pessoa do plural indica a posição de apoio sua equipe editorial as ações de moralização da cidade, bem como seu papel ativo ao cobrar e apelar para ações da Justiça que contribuam com a eliminação da vagabundagem. Além disso, ao relacionar medidas policiais e judiciais no processo de moralizar a cidade o periódico contribui na associação entre crime e moralidade. Com base em matérias como esta consideramos o caráter ativo da imprensa na constituição das masculinidades e feminilidades ditas transgressoras e criminosas.

Dessa feita, assim como as ações da companhia de terras e da administração pública influenciavam a constituição do espaço da cidade, também o Jornal Folha do Norte do Paraná atuava como uma voz ativa no social ao apresentar edições sistemáticas, que se organizavam de maneira a veicular de forma interessada uma síntese do dia, problematizando e produzindo análises e soluções para os problemas locais. Nesta perspectiva, o conhecimento da equipe editorial do periódico permite identificar as vozes presentes nas edições, bem como contextualizar as escolhas editoriais, como a linguagem, as fotografias e a diagramação empregada. Tudo isso nos dá conta das intenções e das expectativas do Jornal, “[...] além de fornecer pistas a respeito da leitura de passado e de futuro compartilhada por seus propugnadores, das ligações cotidianas com diferentes poderes e interesses financeiros, aí incluídos os de caráter publicitário" (LUCA, 2008, p. I38).

Nesse sentido, cabe mencionar alguns aspectos contextuais do processo de constituição da Folha do Norte do Paraná, periódico que seria idealizado pelo bispo diocesano D. Jaime Coelho, cuja intenção era criar “[...] um meio de comunicação do Evangelho, da Palavra de Deus, neste Norte do Paraná" (ROBLES, 2007, p. 214). A partir de 
tais objetivos iniciou-se a captação de doações e a venda de ações, assim se realizando a aquisição dos primeiros equipamentos, a organização da rede de distribuição com base nas paróquias da região e a contratação da equipe, que foi composta por padres, radialistas, jornalistas amadores e estudantes. Inaugurado em 1962 o Jornal ainda em seus anos iniciais passou por uma série de dificuldades financeiras e administrativas, sendo arrendado em 1965 a Joaquim Dutra, Samuel Silveira e seu grupo.

A equipe mobilizada por Joaquim Dutra e Samuel Silveira, donos de outros meios de comunicações na cidade, como estações de rádio e $\mathrm{TV}^{\mathrm{I}}$, foi responsável pela construção de uma nova fase no desenvolvimento do Jornal, que se estenderia entre os de I965 a 1973. Neste período, mesmo mantendo algumas características anteriores, como o esquema de distribuição e a influência do bispo como diretor fundador, as mudanças gráficas propostas permitiram a apresentação e a leitura mais dinâmicas do periódico, chegando a aumentar as vendas de anúncios, tornando o periódico cada vez mais comercial. Estes fatores garantiram uma constância e regularidade aos discursos apresentados pelo Jornal, estendendo sua zona de influência e relevância social

Neste contexto a Folha do Norte do Paraná se constituiu, ao lado dos administradores públicos, enquanto uma mediadora, uma autora que fomenta a adesão ou o dissenso da população a uma causa, mobiliza a sociedade para a ação, articula, divulga e dissemina projetos, ideias, valores e comportamentos. Assim, conforme argumentam Cruz e Peixoto, temos que buscar entender os jornais enquanto elemento constitutivo do social "[...] que detém uma historicidade e peculiaridade própria, e requer ser trabalhada e compreendida como tal, desvendando, a cada momento, as relações imprensa/sociedade, e os movimentos de constituição e instituição do social que esta relação propõe" (CRUZ; PEIXOTO, 2007, p. 258). Sendo assim, analisamos os discursos presente no Jornal com a finalidade de problematizar como esse periódico, a partir de um projeto de sociedade moldou masculinidades e feminilidades.

\section{As 14 prostitutas apreendidas na blitz policial}

Em 15 de novembro de 1969 a Folha do Norte do Paraná publicou a seguinte notícia intitulada "I4 Mulheres Foram Presas em Nova "Blitz" Policial". Este texto publicado na

\footnotetext{
I Cabe destacar que Joaquim Dutra também se envolveu, em I968, com a presidência da Associação Comercial e Industrial de Maringá (ACIM), o que sugere a importância de seus vínculos empresarias para a futura gerência da Folha do Norte do Paraná, a acentuação do caráter comercial do Jornal e a veiculação de matérias que incentivavam a industrialização do município (PAULA, 2006, p. 65).
} 
décima primeira página do Jornal descreve uma ação policial que prendeu algumas mulheres sob a acusação de vadiagem e trotoir ${ }^{2}$, apresentando-as da seguinte forma,

A Polícia de Maringá mais uma vez demonstra de que está realmente preocupada com o bom andamento da lei e da ordem em nossa cidade efetuou ante-ontem à noite, terminando na madrugada de ontem, outra "blitz" para combater o "trottoir" e a vadiagem em Maringá. [...] Fizeram "batida" na Praça Napoleão Moreira da Silva, Avenida Brasil, Vila Operária e na Zona Velha, prendendo as seguintes mundanas: LOURDES FERREIRA, I8 anos, solteira, natural de Videira - SC, filha de Sebastião Ferreira e Ibrantina Ferreira. APARECIDA DOS SANTOS, 26 anos, separada do marido, natural de Araçatuba - SP, filha de José dos Santos e Benedita Alves dos Santos. ROSA MARTINS, 20 anos, separada do marido, natural de Marialva - PR, filha de José Ramires Fernandes e Helena Fernandes. LEONILDA INÁCIO RIBEIRO, 22 anos, solteira, natural de Presidente Prudente, filha de Waldemar Inácio Ribeiro e Helena Fernandes. ROSEMEIRE BUENO, 20 anos, solteira, natural de Apucarana, filha de João Alves Bueno e Cecília Bueno. CLAUDETE NOGUEIRA, I9 anos, separada do marido, natural de Assunção - Paraguai, filha de Raimundo Nogueira e Maria Pereira. MARIA APARECIDA, I8 anos, solteira, natural de Marialva, filha de Pio Barbado e Isabel Reis Barbado. ROSEMEIRE FERNANDES, 30 anos, natural de Presidente Prudente, filha de João Fernandes e Assunta Matricardi. DORALICE FERREIRA, 20 anos, solteira, natural de Arapongas, filha de Vicente Ferreira e Aparecida Ferreira. MARIA TEREZA DA SILVA, 2I anos, natural de Recife, filha de Pidalcino Gomes da Silva e Maria Ferreira. ROSILDA CONCEIÇÃO, I8 anos, solteira, natural de Recife, filha de José Tibutino e Iraci da Conceição. SUZANA BENI (a Marta Rocha), viúva, natural de Campinas, filha de Francisco Beni e Valentina Beni. MARIA LOPES, 30 anos, viúva, natural de Santo Antonio da Platina, filha de Antonio Pereira e Rita Maria da Conceição. MARLENE CARDOSO, I8 anos, casada, natural de Salvador, filha de Sebastião Cardoso da Silva e Ana Moreira da Silva, detida na zona velha quando em companhia de alguns homens fazia algazarra dentro de um bar com as portas fechadas a altas horas da noite. Resistiu aos policiais e a muito custo foi dominada.

${ }^{2}$ Trottoir é o termo utilizado para designar o caminhar que as prostitutas fazem quando ficam à espera de seus clientes. 
Com mais esta ação do Agente Pio e seus agentes, registra-se mais um voto de louvor à Polícia em geral que muito vem fazendo para manter a ordem na cidade (Folha do Norte do Paraná, n. 2040, 15/II/1969, p. II).

Ao utilizar termos como "Blitz" e "Presas" associados a "Trottoir" e "Mundanas" o Jornal constrói alguns sentidos em relação a posturas transgressoras, imorais e criminosas relacionadas a conduta feminina. A figura das prostitutas foi representada e perseguida historicamente por uma série de discursos, como indica Magali Engel (1988) ao argumentar como essas mulheres se tornaram um problema de saúde pública no Rio de Janeiro do século XIX. Segundo a autora, as falas médicas as descreviam e as legitimavam como uma sexualidade pervertida, desviante e antinatural. Nessa perspectiva, tais figuras deveriam ser controladas e isoladas do restante da população, principalmente dos ambientes considerados familiares, uma vez que elas eram tidas como perigo de corrupção aos valores morais. Neste contexto, a criminalização e controle da das prostitutas utilizou a legislação, que não considerava a prostituição um crime ${ }^{3}$, de forma a condenar essas mulheres por outros crimes relacionados a conceitos morais e de manutenção da ordem social, como a vadiagem e a desordem.

O apoio e louvor expresso pelo Jornal às ações policiais com objetivo de garantir o bom andamento da lei na cidade, além contribuir para o controle e a contenção das prostitutas, constitui uma série de discursos sobre essas mulheres as retratando como transgressoras, criminosas, "mulheres da vida”, “doidivanas”, “vadias”, “mundanas”, sendo caracterizadas pelo exercício de sua sexualidade como forma de sobrevivência. Nessa perspectiva, seguindo as proposições de Magali Engel (1988), consideramos que a Folha do Norte do Paraná, assim como o discurso médico, também constituía o meretrício como um problema, um obstáculo à moralização e à higienização do corpo e da sociedade.

Ao caracterizar a prática da prostituição como imoral e criminosa, o Jornal, mesmo sem se dedicar a descrever ou falar especificamente das subjetividades das prostitutas, focalizava seu discurso, principalmente, nas regulações e nas tentativas de controle, vigilância e disciplinarização dessas mulheres. Consideramos como as suas feminilidades eram apagadas, silenciadas e negligenciadas, visto que se afastavam e contradiziam um modelo feminino que se buscava "ideal". Ou seja, as "mulheres da vida", ao não se

\footnotetext{
${ }^{3}$ A partir da instituição do Código Penal Brasileiro pela lei no 2848, de I940, os artigos 229, 230 e 23I condenavam e criminalizavam, respectivamente, a manutenção de casas de prostituição, do rufianismo (ato de explorar a prostituição alheia) e o tráfico de mulheres para o exercício da prostituição considerado crime pelo DecretoLei ${ }^{\circ} 2848$, de 1940 .
} 
encaixarem nos moldes do recato, da maternidade, do casamento, entre outros aspectos associados às figuras femininas, apresentavam uma leitura desviante e transgressora acerca dessas normativas de gênero, sendo enquadradas no discurso da Folha do Norte do Paraná como criminosas.

A busca por uma moralização social presente nos discursos relacionados ao meretrício se alinhavam a elementos do contexto nacional, como a defesa de valores tradicionais, investida pelo regime civil militar em um discurso de ordem e ataque às subversões, bem como ao contexto maringaense e da Folha do Norte do Paraná, contribuindo para embasar e criar as condições necessárias para que as ações de repressão e de controle sobre outras feminilidades que contradiziam o modelo "ideal", se tornassem legítimas.

Seguindo as indicações de Paulo F. de S. Campos (1999), acerca do processo de moralização de Maringá na segunda metade do século XX, acreditamos que o crescimento populacional da cidade entre os anos 1960 e 70, contribuiu para o surgimento de novos sujeitos "desviantes" em um espaço urbano tecnicamente planejado, o que justificaria o acirramento das reclamações, dos pedidos, das campanhas de higienização e de combate ao trottoir. A Folha do Norte do Paraná, constituída enquanto uma mediadora social, nesse contexto trabalhava denunciando e identificando esses sujeitos "transgressores", bem como divulgando textos morais e representações de modelos de condutas "ideais", contribuindo para associação entre o controle do meretrício e a construção de uma imagem de Maringá planejada, moderna, racional e civilizadora, na qual esses sujeitos considerados "desviantes" deveriam estar sobre constante controle.

Ao apresentar as mulheres apreendidas pela polícia o Jornal veicula seus nomes, idade, naturalidade, estado civil e parentalidade, além de indicar os locais em que essas "blitzs" policiais ocorreram. Esse mecanismo de identificar as mulheres e divulgar os locais de meretrício, por meio de manchetes chamativas e falas de autoridades policiais, como delegados e coronéis colaboravam para legitimidade das notícias. Além disso, as escolhas da diagramação, como o uso de letras maiúsculas para destacar os nomes das prostitutas do restante do texto, como publicado no texto anteriormente transcrito, alinhados a outros mecanismos ajudavam na constituição de uma imagem negativa das prostitutas.

A partir das informações apresentadas no texto sobre essas mulheres podemos inferir acerca de suas movimentações, principalmente, pela constatação de que elas vinham de diferentes lugares, o que indica a existência de redes de sociabilidades, comunicação e apoio entre elas algo que lhes garantia a sobrevivência e se constituíam enquanto estratégias de 
existência. De acordo com Ivonete Pereira (2004), em seu estudo sobre a prostituição em Florianópolis entre os anos 1900 e I940, concebemos esse deslocamento como uma forma de resistência e de sobrevivência adotadas pelas prostitutas. Inseridas em uma sociedade que valorizava a virgindade e o recato feminino, as "mulheres da vida" não usufruíam de proteção pública, visto que a sua relação com o poder policial pressupunha a repressão. Ao serem desqualificadas dessa maneira, as prostitutas buscavam garantir a sua existência por meio de mecanismos e estratégias como a mobilidade, “[...] que, ora por pressão dos vizinhos, ora por pressão de polícia, ou ainda por conveniência, constantemente mudavam de residência, afastando-se cada vez mais do centro da cidade, que, mesmo lentamente, urbanizava-se e exigia a 'limpeza' dos locais” (PEREIRA, 2004, p. 2I).

Dessa maneira, consideramos que a demarcação de quem eram essas mulheres e dos lugares em que circulavam se constituía em uma das peças importantes no jogo de visibilidade que, segundo Michel Foucault (2004), tem por função garantir a vigilância constante dos sujeitos, sendo este o princípio identificado na estrutura do panóptico. Essa estratégia disciplinar proporcionava, portanto, a observação, o registro, a classificação, o controle das atividades e uma distribuição espacial funcional da população.

Por meio desses dispositivos do poder inferimos que as notas policiais exerciam um papel importante na organização espacial dos sujeitos. Sendo assim, as matérias do Jornal, ao veicularem determinados sujeitos, suas práticas e as qualificarem, alinhadas a instituições, estruturas arquitetônicas, leis, medidas administrativas, enunciados científicos, proposições morais, religiosas e filosóficas que, propagadas pelo tecido social, se materializavam nos gestos e nas práticas, colaboravam para a gratificação e ascensão social de uns e as penalidades e isolamento de outros.

A vigilância e repressão policial imposta às "mulheres da vida" negava, muitas vezes, a livre circulação e o acesso às ruas, principalmente, às localizadas no Centro e nas áreas comerciais de Maringá, uma vez que esses locais eram públicos e deveriam ser de acesso a toda população. Compreendemos que essa regulação e disposição dos sujeitos na urbe estava relacionada com a organização do poder disciplinar na sociedade. Assim, como considera Foucault (2004), os poderes disciplinares funcionavam a partir de uma apropriação do corpo, controle do espaço e decomposição do tempo de maneira contínua, em que os principais alvos eram os anormais, ou seja, doentes mentais, as prostitutas, os criminosos, etc.

Ao tornar as prostitutas visíveis e alvos do controle e da vigilância dos vizinhos, da população e da polícia, a Folha do Norte do Paraná, também constituía discursos sobre os 
espaços ao associá-los a prática da prostituição como a Praça Napoleão Moreira da Silva, Avenida Brasil, Vila Operária e Zona Velha. Sendo assim, seguindo as indicações de Michel De Certeau (20I4), segundo o qual os espaços são constituídos pelas práticas e discursos que ali se desenvolvem, compreendemos que os conjuntos de narrativas fragmentados fundam, articulam, descrevem, fixam, delimitam os lugares, por fim "os relatos são cotidianos contam aquilo que, apesar de tudo, se pode aí fabricar e fazer. São feituras de espaços" (CERTEAU, 20I4, p. I89). A partir dessas características e da relação do discurso e dos lugares é que eram constituídas determinadas performances dos sujeitos em sua circulação pela cidade. Ponderamos por meio desse conceito como o periódico e os indivíduos influenciavam e eram influenciados pelos ambientes que frequentavam.

Além das interdições relacionadas a ocupação dos espações e circulação, outra interdição que percebemos em relação ao discurso da coluna policial acerca da prostituição se encontra no silenciamento em relação as formas de comportamento, gestos, maneiras de falar, vestir e trejeitos das prostitutas. Essa característica do conteúdo do Jornal nos indica como as prostitutas eram definidas e enxergadas pela sociedade apenas pelo aspecto da prostituição, sendo apagadas as suas vivências para além do encontro com o poder policial e da repressão. Era silenciado o que mais essas mulheres poderiam dizer sobre o seu cotidiano, uma vez que elas estariam fora da ordem do discurso por não participarem ou não cumprirem os rituais compartilhados pelos membros que construíam o periódico. Assim, a discussão da prostituição no Jornal se restringia, em especial, a aspectos como o controle/vigilância das mulheres, associando a prostituição apenas ao universo feminino. Dessas "mulheres da vida" podemos inferir apenas que eram mulheres itinerantes, em constante trânsito.

\section{O caso perdido de Benedito Mariano}

Benedito Mariano foi um nome recorrente nas edições da coluna policial da Folha do Norte do Paraná no ano de I969, sendo constantemente apreendido pela polícia sob a acusação de desordem decorrente do abuso de bebidas alcoólicas. O discurso da Folha do Norte do Paraná em relação ao consumo das bebidas alcoólicas, em um primeiro olhar pode parecer ambíguo e contraditório. No entanto, quando nos atentamos aos recortes sociais percebemos que a prática de consumir álcool associada aos populares, era um ato de lazer estigmatizado e condenado pelo Jornal, constituindo-se em um elemento de descrédito e de desqualificação desses sujeitos. 
Entre os anos 1969 e 1970 as notas acerca das prisões dos embriagados passaram a ser frequentes na coluna policial. Esse aspecto pode ser relacionado com o crescimento da população urbana de Maringá, que, entre as décadas de 60 e 70, praticamente duplicou, introduzindo novos sujeitos no cotidiano da cidade, estranhos à dinâmica, organização e valores veiculados e defendidos no conteúdo do periódico. Ao apresentar esses indivíduos em suas edições, a Folha do Norte do Paraná contribuía para a localização desses homens no espaço urbano e sua hierarquização na sociedade local.

Além disso, esse período compreendia a consolidação e o endurecimento das políticas de moralização e de repressão movidas pela ditadura sobre sujeitos "desviantes", como, por exemplo, os "alcoólatras" e as "prostitutas", o que em parte explicaria o enfoque nas prisões e sua divulgação no Jornal. O encarceramento dessa população seria parte de uma política de contenção daqueles que não se adequavam ao discurso de ordem, progresso e trabalho. Ao nos aproximarmos das reflexões de Sidney Chalhoub (200I), sobre o processo de combate à ociosidade no Rio de Janeiro no início do século XX, concebemos que o Jornal e as autoridades policiais buscavam a vigilância dos populares e o combate à desordem produzida, supostamente, pelos vícios e pelo ócio, considerados um obstáculo à construção de sociedade ordeira.

O Jornal utilizava de uma série de mecanismo para dar destaque as notas policiais relacionadas a prisão de "bebuns", entre eles a apresentação e a ênfase a um indivíduo que era veiculado, frequentemente em suas edições. Benedito Mariano apresentado na Folha do Norte do Paraná pela primeira vez em I6 de outubro de 1969, na nota intitulada "O bêbado do dia", em que era informado que "outra vez. Apenas uma pessoa presa por "entortar" uma "branquinha". O de hoje é BENEDITO MARIANO, detido na Vila Operária aos 45 minutos de ontem" (Folha do Norte do Paraná, n. 2013, I6/Io/1969, p. 7).

Observamos que a organização das notas policiais, nesse processo de (des)qualificação dos indivíduos embriagados, apresentava algumas características gráficas que construíam sentidos e possibilitavam a identificação dos comentários que se referiam a casos de embriaguez. Sendo assim, encontramos elementos-padrões de redação, como a divulgação dos nomes dos presos, dos locais das prisões, o uso de figuras de linguagem, que destacavam o humor, a ironia e o sarcasmo com que eram retratados os "bebuns". Ademais, o uso pontual de letras maiúsculas para identificar os sujeitos, destacando seus nomes, os títulos chamativos e bem-humorados, também buscavam despertar atenção para o conteúdo produzido. 
Além disso, ao nomear essas figuras masculinas, o discurso do Jornal os diferenciava e os individualizava. Esses "bebuns" não representariam todos os homens da sociedade maringaense, eles se restringiam a apenas esses sujeitos identificados na coluna policial. Consideramos que esse processo de individualização dos sujeitos se relaciona com as considerações de Foucault (2004) acerca dos mecanismos de funcionamento das sociedades disciplinares, especialmente em relação à garantia da vigilância dos indivíduos por meio da visibilidade e do contínuo controle do tempo e espaço.

Na publicação do dia 7 de novembro de 1969 notamos, novamente, o nome de Benedito veiculado em letras maiúsculas, facilitando a identificação das notícias relacionadas a esse personagem, a nota dizia:

[...] o famoso BENEDITO MARIANO. O Benedito, desta feita, tomou o maior "pileque" já no Maringá Velho e depois começou a promoção de desordens. Não tem jeito mesmo. Benedito sai da cadeia, algumas horas fora apronta, volta novamente. Já conhece todo mundo lá dentro (Folha do Norte do Paraná, n. 2033, 23/1I/1969, p. 9).

Nesse trecho destacamos como o comportamento recorrente desse personagem o tornava popular, ao mesmo tempo em que a nota infantiliza seu comportamento ao dizer que Benedito sai da cadeia e sempre volta a "aprontar". Ao aproximar a figura desse sujeito a de uma criança malcriada, essas notas policiais reforçavam a incompatibilidade entre o abuso do álcool e a construção de uma masculinidade honrada, viril e de sucesso, constituindo uma outra masculinidade "subordinada" associada à embriaguez, ao descontrole, à criminalidade e à degeneração física e moral.

Ao dar continuidade no acompanhamento dos feitos de Benedito, a Folha do Norte do Paraná veiculou, em 23 de novembro de 1969, a nota "Oh! Benedito", informando que

\footnotetext{
Ele, o maior freguês, o abominável homem da pinga, BENEDITO MARIANO, o bom do copo - campeão halterocopismo, novamente está em cana. Entrou ontem às 2 horas da madrugada detido no Maringá Velho por um guarda noturno. Segundo ele, em "péssimo estado de embriaguez" (Folha do Norte do Paraná, n. 2046, 23/11/1969, p. 9).
}

O trecho acima dedica suas primeiras linhas a apresentar Benedito com um vencedor na arte de se embriagar, para, em seguida, informar a ocorrência de mais uma prisão desse indivíduo. A partir de notas como essa, construímos a hipótese de que o conteúdo produzido 
pelo Jornal em relação a esse sujeito e a outros "embriagados" possuía uma dupla função. Em primeiro lugar, seu discurso desqualifica esses indivíduos, por meio da ironia, do sarcasmo e da zombaria presentes em seus textos, destacando a falta de controle causada por essa prática. Em segundo lugar, essas menções eram alertas e avisos as/os leitoras/es para os perigos da falta de moderação em relação ao consumo do álcool.

Uma retomada histórica acerca dos posicionamentos e debates sobre o consumo de bebidas alcóolicas, especialmente, daqueles produzidos no início do século XX, em que em meio a um contexto de modificações no espaço e na produção industrial as discussões sobre o álcool eram protagonizadas pelo Estado, pela medicina higienista e indústria de bebidas alcóolicas. Neste contexto, o recorte de classe em relação ao consumo alcóolico se impunha de maneira que se acreditava na degeneração dos populares e trabalhadores, ao mesmo tempo em que as propagandas estimulavam a sua aquisição pelas classes altas e médias (SAVIAN, 20I3).

A bebida, portanto, pode ser compreendida como um ato social, principalmente, a partir do espaço dos bares, refletindo a relação consumo alcoólico e sociabilidade masculina. Isto é, o ato de beber se masculinizava, era significado como um aprendizado do código masculino, no qual os bares eram palcos de masculinidade onde o excesso era considerado negativo e degenerativo, enquanto a socialização pela bebida era carregada com uma carga positiva.

As constantes prisões de Benedito e o destaque de seu nome na coluna policial faziam com que os leitores com facilidade o localizassem dentro do periódico e acompanhassem sua vida, através do discurso do Jornal, como uma sucessão de peripécias. Isso o podemos observar na nota de I8 de novembro, intitulada "Eta Benedito", em que o sujeito é preso por estar bêbado e causar desordem em uma churrascaria. O texto dizia: "Com o BENEDITO MARIANO na pinga não há quem possa. Não há de ver que ele 'aprontou' novamente. [...] já está tão acostumando a ser preso que até nós estranhamos o dia em que seu famoso nome não acontece nesta coluna. E o motivo é sempre o mesmo: pinga" (Folha do Norte do Paraná, n. 204I, I8/II/1969, p. 9). Sendo assim, sua prisão passava a ser tratada de forma rotineira seria ele o personagem constante e famoso no espaço das notas policiais.

Além disso, observamos como o uso do humor como elemento discursivo nas notas relacionadas aos casos de embriagues e a Benedito se diferenciavam das outras "transgressões" veiculadas na coluna policial, que destacam a violência, o sensacionalismo ou o apelo moral. Inferimos que o recurso humorístico empregado nessa espécie de conteúdo se constituía enquanto um mecanismo que colaborava para desacreditar e 
desqualificar esses sujeitos, que transgrediam um modelo de masculinidade forte, viril e moderada, sendo considerados degenerados físicos e morais, obstáculos à consolidação de valores burgueses e capitalistas, como indica Maria Izilda Santos de Matos (200I) sobre as campanhas antialcoólicas no Brasil do início do século XX.

A notícia publicada em 25 de novembro de I969, sob o título “Será o Benedito?”, como uma brincadeira baseada no ditado popular que se refere a situações indesejáveis, fora veiculada mais uma prisão de nosso personagem. No texto era veiculado que "[...] ele é mesmo incorrigível. [...] E cada vez que o prendem é em lugares diferentes. Desta vez estava lá no Edifício Genko, “aprontando” uma das suas. Não adianta, Benedito! Você nunca vai conseguir acabar com a pinga da cidade" (Folha do Norte do Paraná, n. 2047, 25/1I/1969, p. 9). Inferimos que ao caracterizar Benedito como "incorrigível” "aprontando' uma das suas" o Jornal contribui para a construção da relação entre o descontrole relacionado à embriaguez e à falta de moderação como aspectos que diminuíam o valor social desses homens e os afastava de uma masculinidade ideal, tornando-os desordeiros, ladrões e vadios. De acordo com Vanderlei Machado (2007), os jornais e as ações policiais colaboravam no processo de qualificação e de desqualificação de determinados sujeitos masculinos, contribuindo para a sua ascensão social ou para o seu isolamento.

Por fim uma das últimas publicações que identificamos sobre Benedito fora publicada em 27 de novembro de I969, veiculando que,

Mais uma vez, o inveterado 'bebum' foi recolhido ao xadrez. BENEDITO MARIANO não se entende: não se sabe se ele gosta de ir preso ou gosta de beber. A verdade é que ele não sai da cana devido à cana. Pelo menos os nomes conjuminaram. Já fizeram até uma sugestão dar um prêmio ao BENEDITO quando ele completar mil prisões: como vítima, claro (Folha do Norte do Paraná, n. 2049, 27/II/1969, p. 9).

Nas linhas acima, assim como nas notas anteriores, nós nos aproximamos de Benedito Mariano, que, apesar de nos parecer muito próximo e familiar por estar presente quase que diariamente nas edições da coluna policial, nos é um estranho, visto que conhecemos apenas um aspecto de sua vida, qual seja, a desordem e o descontrole causado pelo consumo excessivo de álcool. Nesse sentido, muitas perguntas rodeiam a figura de Benedito: Será que ele tinha família, filhos? Era casado? Qual a sua idade? Possuía um emprego? Onde e como vivia ou quando se iniciou seu problema com bebidas alcoólicas? 
Talvez esses outros aspectos que envolviam a vivência de Benedito poderiam nos ajudar a compreender quem era esse homem e qual era a sua história. A partir do que nos informa o Jornal tratava-se de um sujeito alvo de zombaria da imprensa, desacreditado socialmente, mas que também era o bêbado camarada, amigável, não violento e que, possivelmente, constituiu uma rede de sociabilidade com os policiais, donos de bares e demais cidadão lhe eram próximos e garantiam sua sobrevivência.

Essa subjetividade desviante, representada por Benedito, pode ser compreendida enquanto uma resistência, microluta e relação de poderes. Esses indivíduos nos permitem pensar acerca do alcance da ação do discurso e de como suas indicações moralizantes e normativas incidiam sobre os sujeitos. Acreditamos que os conteúdos produzidos pelo Jornal eram assimilados de diferentes maneiras pelos indivíduos leitores. Assim, a presença de "embriagados" na cidade tecnicamente planejada indicava a não conformidade ou o não alinhamento, ainda que inconsciente, desses homens a um discurso que buscava reafirmar uma masculinidade moderada e controlada.

Assim, o conteúdo presente na coluna policial acerca das masculinidades denunciava um modelo de masculinidade "subordinada" e "desacreditada", que se opunha a uma série de preceitos morais, considerados pelos grupos dominantes da sociedade de Maringá e pela Folha do Norte do Paraná, como base do desenvolvimento local, sendo eles a força, o esforço e o trabalho como lei suprema e reforço de uma masculinidade que se buscava hegemônica. O homem embriagado, por sua vez, era, ao contrário, ocioso, pervertido, violento, desordeiro, degenerado físico e moralmente.

O discurso do Jornal sobre essas masculinidades, de acordo com as contribuições de Butler (20I6) sobre a construção dos gêneros, entendidos como uma prática discursiva contínua, estilizada por um conjunto de atos repetidos no interior de uma estrutura reguladora rígida, nos permite notar que o desregramento e o descontrole diante do consumo de álcool desafiavam e se contrapunham à constituição de uma masculinidades hegemônica, pautada na moderação, na força, na virilidade, na elegância e no comprometimento com o desenvolvimento social da cidade.

Ademais, com base nas indicações de Sidney Chalhoub e a partir dos aspectos apresentados, podemos inferir que, mesmo o Jornal buscando construir linhas divisórias e dualidades acerca das subjetividades e dos espaços masculinos,

[...] o sistema se caracteriza por uma linha que une o mais moral ao menos moral no universo ideológico, e o mais rico ao mais pobre na estrutura 
social. Neste sentido, não há um dualismo, uma oposição entre dois mundos diferentes, isto é, não há um mundo do trabalho e outro da ociosidade e do crime - há, na verdade, apenas um mundo, coerente e integrado na sua dimensão ideológica. Não faz sentido, então, pensar o ocioso e o criminoso como indivíduos que vivem à margem do sistema, marginais em relação a um suposto mundo da ordem. Cabe pensar a ociosidade e o crime como elementos constituintes da ordem e, mesmo, como elementos fundamentais para a reprodução de um determinado tipo de sociedade (CHALHOUB, 200I, p. 79).

Compreendemos que uma separação categórica dos sujeitos, como encontramos em algumas páginas do Jornal, se restringia ao discurso da Folha do Norte do Paraná, uma vez que ambos estes diversos indivíduos pertenciam a uma mesmo espaço urbano, a uma mesma organização social, que assim os constituía como um mecanismo de manutenção da ordem. Isto é, aqueles indivíduos que se aproximavam ou se distanciavam de um modelo de masculinidade que buscava se firmar enquanto "ideal" eram complementares e necessários entre si.

Além disso, como pontua Chalhoub (200I, p. 79), a existência “[...] do crime tem uma utilidade óbvia quanto interpretada do ponto de vista da racionalidade do sistema: ela justifica os mecanismos de controle e sujeição dos grupos sociais mais pobres”. Nessa perspectiva, a denúncia dos "pinguços" nas notas policiais se configurava como uma justificativa para o controle e para a desqualificação desses indivíduos que possuíam uma leitura divergente acerca das normativas e dos modelos da masculinidade "ideal".

Enquanto o ideal de masculinidade estava baseado em "[...] sua capacidade de ação, praticidade e objetividade, sucesso, força e iniciativa, e vinculavam-se os atributos da virilidade ao trabalho, que deveria desempenhar uma função central na vida do homem" (MATOS, 200I, p. 42) e "[...] um ideal de masculinidade, exprimindo e condicionando o ser homem e trabalhador nesse período" (MATOS, 200I, p. 4I). Os conteúdos analisados reforçavam os discursos que apontavam para os homens "bebuns" como vadios, descontrolados, degenerados e pervertidos pelo vício, que eram desqualificados e desacreditados pelos comentários e pelas zombarias presentes na coluna policial.

\section{Considerações finais}


A partir do objetivo de analisar as masculinidades e as feminilidades ditas transgressoras e criminosas, presentes na Folha do Norte do Paraná, entre os anos de 1965 a 1973, nos atentamos às figuras das prostitutas e bebuns. Dessa maneira, relacionamos os posicionamentos do Jornal em relação à prostituição e ao alcoolismo, ao crescimento urbano de Maringá, entre os anos 1960 e 1970, bem como a busca pelo desenvolvimento econômico da cidade, contribuindo para o processo de repressão a sujeitos ditos "desviantes", como as prostitutas.

Os discursos sobre a prostituição e o alcoolismo em Maringá estavam inseridos em narrativas sobre a cidade que buscavam a construção de um espaço urbano ordeiro, moderno, centro do desenvolvimento regional, fundado a partir de um processo de ocupação planejado e racional, erguida pelas figuras heroicas dos pioneiros. Nesse contexto, a Folha do Norte do Paraná, de acordo com os vínculos de sua linha editorial, localizados e coniventes com tal discurso, assim como o poder público e policial, influenciariam na constituição do entendimento do que eram condutas consideradas criminosas, bem como quem eram esses sujeitos.

De tal modo, assim como na repressão à prostituição, notamos que as ações das autoridades policiais e do periódico se somavam no enquadramento dos alcoólatras da cidade, entretanto o tratamento dado ao consumo em excesso de álcool possuía algumas particularidades. Entre elas o tom de zombaria que perpassa as notas policiais acerca das prisões dos indivíduos embriagados, diferente do aspecto condenatório e moralizante das notícias sobre a prostituição. Essa diferenciação da escrita do Jornal e na ação policial no tratamento entre os sujeitos masculinos e femininos, se materializava no número de campanhas organizadas contra a prostituição, no tom e nos adjetivos empregados pelo discurso. A especificidade da produção discursiva sobre esses sujeitos está relacionada com a posição que eles ocupavam na estrutura do gênero e na sociedade, em que os "bebuns" são apenas desqualificados e ironizados, enquanto que sobre as prostitutas recai o policiamento de suas posturas, comportamentos e corpos enquanto um espaço subalterno em cerceamento, disputa, controle e cuidado, reforçando a complementariedade e oposição dos sujeitos investigados nesta pesquisa.

\section{Referências}

BUTLER, Judith. Problemas de gênero: feminismo e subversão da identidade. Rio de Janeiro: Civilização Brasiliense, 2016. 
CAMPOS, Paulo Fernando de S. Moralizando o pobre: vadios, baderneiros e loucos na "cidade tecnicamente planejada para ser bela e sem problemas". DIAS, Reginaldo B.; GONÇALVES, José H. R. Maringá e o norte do Paraná. Maringá, PR: Editora da UEM, I999, p. $315-331$.

CERTEAU, Michel de. A invenção do cotidiano: I. Artes de fazer. Petrópolis, RJ: Vozes, 2014. CHALHOUB, Sidney. Trabalho, lar e botequim: o cotidiano dos trabalhadores no Rio de Janeiro da Belle Époque. Campinas, SP: Editora da Unicamp, $200 I$.

CHIES, Cláudia; YOKOO, Sandra Carbonera. Colonização do Norte Paranaense: avanço da cafeicultura e problemas decorrentes deste processo. Rev. GEOMAE, v.3, n. I, p. 27-44, 2012.

CRUZ, Heloísa de Faria; PEIXOTO, Maria do Rosário da Cunha. Na oficina do historiador: conversas sobre a história e imprensa. Revista Projeto História, São Paulo, n. 35, p. 253-270, 2007 .

ENGEL, Magali. Meretrizes e doutores: saber médico e prostituição no Rio de Janeiro (I840I890). São Paulo: Brasiliense, 1988.

FOUCAULT, Michel. Vigiar e punir. Petrópolis, RJ: Vozes, 2004.

LUCA, Tânia Regina de. História dos, nos e por meio dos periódicos. In: PINSKY, Carla Bassanezi. Fontes históricas. 2. ed. São Paulo: Contexto, 2008. p. II3-I53.

MACHADO, Vanderlei. Entre Apolo e Dionísio: a imprensa e a divulgação de um modelo de masculinidade urbana em Florianópolis (I889-1930). Tese (Doutorado em História) Universidade Federal do Rio Grande do Sul, Porto Alegre. 2007.

MATOS, Maria Izilda. Meu lar é o botequim: alcoolismo e masculinidade. São Paulo: Companhia Editora Nacional, 200I.

OLIVEIRA, Semí Cavalcante de. A economia cafeeira no Paraná até a década de I970. Vitrine da Conjuntura, Curitiba, v. 2, n. 4, 2009.

PAULA, Antônio Roberto de. O jornal do bispo: a história da Folha do Norte do Paraná. Disponível em: http://jornaldobispo.blogspot.com/20Io/o4/livro-o-jornal-do-bispo-historiada.html. Acesso em: 25 jan. 2016.

PEREIRA, Ivonete. “As decaídas”: prostituição em Florianópolis (I900-I940). Florianópolis, SC: Editora da UFSC, 2004. 
SCOTT, Joan. Gênero: uma categoria útil para a análise histórica. Cadernos Pagu, Campinas, n. 3, p.II-27, I994.

ROBLES, Orivaldo. A Igreja que brota da mata. Maringá, PR: Dental Press, 2007.

SAVIAN, Zulemar Augusta Girotto. Gênero, Masculinidades e Alcoolismo: Brasil no início do século XX. Revista Cadernos De Clio, Curitiba, n.o 4, p. I69-200, 2013.

TOMAZ, Paulo César. A região norte do Paraná e a formação da cidade de Maringá. Revista Semina, v. 8, n. 2, p. I-I9, 2010.

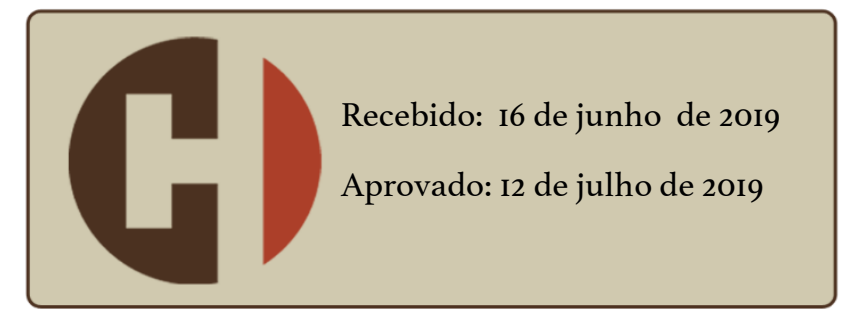

